Conclusions Our analysis suggests a limited impact of the MCA on $\mathrm{PoD}$ for $\mathrm{HF}$ patients lacking capacity, perhaps reflecting greater complexity of care required of that clinical cohort.

\section{P48 ADVANCE CARE PLANNING LEAD TO BETTER DECISION MAKING FOR END-OF-LIFE CARE IN PATIENTS WITH PROGRESSIVE IDIOPATHIC PULMONARY FIBROSIS}

I Owan*. National Hospital Organization, Okinawa Hospital, Okinawa, Japan

\subsection{6/spcare-2019-ACPICONGRESSABS. 131}

Idiopathic pulmonary fibrosis (IPF) is a progressive and ultimately fatal lung disease. The majority of IPF patients die in hospital settings in Japan not only due to severe symptoms but also late end-of life (EOL) decision. This report presents four cases where advance care planning (ACP) allowed patients to choose their own EOL setting. Case $170 \mathrm{~s}$ male with IPF for 3 years with a stable condition but eventually worsen due to pneumothorax. Through ACP, he chose his home as the place of death. Case $260 \mathrm{~s}$ male with IPF for 8 years but conditions eventually worsen due to severe pulmonary hypertension caused by pulmonary embolisms (PE). After ACP, he decided to remodel the house, allowing him to stay at home for 20 days before dying Case 370 s female diagnosed with familial IPF 3 years ago but conditions worsen due to acute heart failure due to PE. After recovering 7 months later, she decided to move to a nursing home through ACP. Case 4 70s male with IPF for 12 years, with existing malignant lymphoma, the condition gradually deteriorated leading to the decision to stay at a hospice through ACP

In conclusion, ACP was helpful in the cases mentioned above as it gave the patients the power to make their own decision. Although, medical professionals tend to lean towards disease-centered management they understand the difficulties in deciding the best timing to discuss EOL issues so that patients will not lose hope too early on

\section{P49 HOW TO TRANSLATE AN ADVANCE CARE PLANNING (ACP) CONVERSATION IN A FUTURE CARE TREATMENT PLAN? THE ACP-NOPA WEB APPLICATION}

${ }^{1}$ B Loupatatzis", ${ }^{1}$ I Karzig, ${ }^{2} \mathrm{M}$ Obrist, ${ }^{1}$ Th Otto, ${ }^{3} \mathrm{~A}$ Weber, ${ }^{1} \mathrm{~T}$ Krones. ${ }^{1}$ University Hospital of Zurich, Zurich, Switzerland; ${ }^{2}$ Palliative ch, Bern, Switzerland; ${ }^{3} G Z O$ Spital Wetzikon, Wetzikon, Switzerland

\subsection{6/spcare-2019-ACPICONGRESSABS. 132}

Background The application was developed 2016 in Switzerland. The tool combines the different concepts of ACP, shared decision making (SDM) and medical emergency planning. In step one all documents and decision aids to create a living will are provided. Depending on the specifications the patient made in the living will (especially concerning treatment intensity and last-place-of-care) during step 2 the tool supports the care team in discharge management and/or creating emergency plans. The underlying illness of the patient is considered by providing the likely symptoms and giving treatment suggestions for the case of an emergency situation.

Methods The tool and the underlying educational program were developed based on our experiences with the MAPS trial (a randomized controlled trial) and palliative emergency planning to support professional care givers in conducting an
ACP conversation and creating a living will based on SDM and to translate both in concrete treatment planning and future treatment planning in case of decisional incapacity. The tool was implemented in the Kanton of Zurich and tested in a feasibility study with piloting teams.

Results We will present our concept and the results of the feasibility study.

Discussion Core competences of ACP, SDM, intensive and palliative care are combined in this web application to support professional care givers in creating highly individualized emergency treatment plans for severely ill, multimorbid or elderly nursing home patients. Providing caregivers with these combined competences is a good way to help patients to get their treatment of choice in their favorite place-of care.

\section{P50 ADVANCE DIRECTIVES INCLINATION OF PATIENTS IN SINGAPORE - A QUALITATIVE STUDY}

JCQ Wong*, CSL Lau, LY Teo, CY Khoo, CT Ng, LLH Chan, JK Loh, KLD Sim. National Heart Centre Singapore, Singapore, Singapore

\subsection{6/spcare-2019-ACPICONGRESSABS.133}

This study aims to understand which of the advance directives (ADs) i.e. Advance Care Planning (ACP), Advance Medical Directive (AMD) and Lasting Power of Attorney (LPA) patients are more inclined to.

The study was conducted from March to September 2018 in our institution. Patients aged 21 to 99 were asked to complete a survey to evaluate their awareness, perceptions and receptions on the ADs.

Out of 150 patients, the awareness was 101 for LPA, 77 for AMD and 74 for ACP with 41.3\%, 28.6\% and 20.7\% of them learnt about them through media respectively. 55 out of 101 patients considered doing LPA. 51 out of 77 patients considered doing AMD. 40 out of 74 patients considered doing ACP. $70 \%$ of those considering doing $\mathrm{ADs}$ are influenced by their family. 38.6\% of them favoured LPA over ACP and AMD as financial arrangement is made. $30 \%$ of them prefer AMD to ACP as AMD is legal-binding. 36\% of them prefer ACP to AMD as they get to discuss their healthcare preferences with their caregivers. $48 \%$ of them think it is too early to talk about end-of-life treatments. $51.3 \%$ of them do not know the process of doing ACP and AMD.

There is no significant trend showing which ADs are patients more inclined to. Healthcare providers could initiate ACP conversations when patients are at their early disease trajectory. Also, more can be done to increase ADs awareness especially ACP through media to educate public on their importance and processes.

\section{P51 EVALUATION OF THE ADVANCE CARE PLANNING PROGRAMME IN A CARDIAC CENTRE IN SINGAPORE}

CSL Lau*, JCQ Wong, LY Teo, CY Khoo, CT Ng, LLH Chan, JK Loh, SM Lim, Ng CSH, SH Tan, G Wong, BC Tan, DKL Sim. National Heart Centre Singapore, Singapore, Singapore

\subsection{6/spcare-2019-ACPICONGRESSABS. 134}

Our institution has initiated inpatient Advance Care Planning (ACP) programme since 2013. However, enrolment rate has been low. We plan to report our experience after extending ACP programme to outpatient setting in 2017. 